\title{
"CELEBREMOS EL PREMIO CONCEDIDO AL JOBEN QUE ÇELEBRA EUTERPE I CLÍO” JUAN DE LA CUEVA Y GUADALAJARA
}

Hace más de un siglo se dijo que los hermanos Juan (1543-1612) y Claudio de la Cueva (1551-1611) residieron en Guadalajara, adonde el segundo, racionero hasta entonces en México, había recibido una prebenda más suculenta en la catedral de Nueva Galicia. No había por qué dudarlo, ya que el poeta había compuesto de su puño y letra una canción petrarquista, en recuerdo del evento, "al dotor Claudio de la Cueva, inquisidor apostólico \&c., aviéndole dado el arcedianato de Guadalajara en las Indias de Nueva España"1. La letra siempre ha impreso respeto, y aún más siendo manuscrita, autógrafa y de siglos pretéritos.

Pero de ahí a asegurar que el eclesiástico "fut nommé archidiacre à Guadalajara et que le poète l'y accompagna et y resta algunos años" media aún bastante trecho². Tanto como suponer que la elegía IX de Obras de Ivan de la Civeva (1582) ${ }^{3}$ pudo haber sido escrita en Guadalajara, la "inculta i vil aldea/ donde me falta el seso i la paciencia" desde la que se queja nuestro Cueva ${ }^{4}$. Mal debió de pasarlo en un lugar tan denostado, si hacemos caso al "justo i cruel castigo" a que lo condenaba entonces un amor en ausencia que le producía "pena", "ansia" y "desventura" en gozoso acatamiento del código de Petrarca. Pero no fue en la capital neogallega, sino en la villa de Aracena - sitio, en el decir del maestro Juan de Mal Lara, de "mucha fruta, caça" y el más principal "de salar tocinos, que es la mejor prouisión que en las carnes muestra Galeno" $-^{5}$ donde redactó su elegía. Mucho antes,

\footnotetext{
${ }^{1}$ De las rimas de Ivan de la Cveva primera parte, ms. 53-3-4 de la Biblioteca Capitular de Sevilla, f. 125v.

${ }^{2}$ Fredrik A. WulfF, Poèmes inédits de Juan de la Cueva publiés d'après des manuscrits autographes conservés à Seville dans la Bibliothèque Colombine, t. 1: Viage de Sannio, Malmström, Lund, 1887, p. xlv.

${ }^{3}$ Andrea Pescioni, Sevilla, ff. 67v-69r.

${ }^{4}$ F. A. WulfF, op. cit, p. vii.

${ }^{5}$ Recebimiento que hizo la muy noble y muy leal ciudad de Seuilla a la C. R. M. del rey D. Philipe N.S., Alonso Escrivano, Sevilla, 1570, f. 111r.
} 
además, del viaje de uno y otro a Nueva España ${ }^{6}$. Que no pergeñó esos versos en Guadalajara sino "en una aldea andaluza, desde donde dirigió a sus amigos otras muchas composiciones", lo advirtió -aunque sin demostración alguna-Francisco A. de Icaza, quien no albergaba duda de no existir constancia de que el poeta hubiese radicado en la ciudad?.

Que tales palabras valieron de poco lo atestigua que se aseverara luego que Cueva "estuvo en Guadalajara”, en cuya Iglesia Claudio ejerció funciones de "inquisidor y arcediano" y, que, a no dudarlo, compuso allá la elegía IX, ya que era entonces "la inculta aldehuela de Juan de la Cueva", lugar de "pocos vecinos, destartalados edificios y sin manifestaciones de la vida intelectual"8. Menéndez Pelayo, con su autoridad, contribuyó a propagar el error al insistir en que vino a Nueva España acompañando al "inquisidor y arcediano de Guadalajara" y en que el viaje tuvo efecto entre 1588 y $1603^{9}$. Así, continúa todavía aludiéndose al "hermano del arcediano de Guadalajara"10 e insistiéndose en que Claudio se avecindó en la capital de Nueva Galicia ${ }^{11}$.

Los hermanos De la Cueva llegaron a Veracruz a fines de septiembre de 1574, tras un penoso viaje repleto de percances. Arribó también en esa flota el licenciado Lorenzo Sánchez de Obregón, nombrado por el presidente del Consejo de Indias primer corregidor de México por provisión de 13 de diciembre de 1573. El arzobispo Moya de Contreras, enemistado con el virrey don Martín Enríquez por asuntos de mucha o poca monta ${ }^{12}$, se congratuló de que sus diligencias restringieran la potestad de oidores y alcaldes, "que procedían como compadres". "El Virrey no ha gustado mucho de su venida - prosigue el prelado en su carta a Ovando- porque no querría hombres que tuviesen ser ni poder, sino que todos se gobernasen por su voluntad"13. El 14 de octubre de 1574 juró ante la Audiencia ejercer su oficio con imparcialidad "conforme a las leyes" y no acep-

${ }^{6}$ José Cebrián, Estudios sobre Juan de la Cueva, Universidad, Sevilla, 1991, p. 63.

${ }^{7}$ Francisco A. De Icaza, Sucesos reales que parecen imaginados de Gutierre de Cetina, Juan de la Cueva y Mateo Alemán, Hernando, Madrid, 1919, pp. 104-105.

8 José Cornejo Franco, "La literatura en Jalisco", Boletín de la Junta Auxiliar Jalisciense de la Sociedad Mexicana de Geografía y Estadística, 4 (1935-36), p. 127.

${ }_{9}^{9}$ Marcelino Menéndez Pelayo, Historia de la poesía hispanoamericana, Victoriano Suárez, Madrid, 1911, t. 1, p. 33.

10 Alfonso Méndez Plancarte, Poetas novohispanos. Primer siglo (1521-1621), UNAM, México, 1991, p. xxii.

${ }^{11}$ Margarita Peña Muñoz, "Juan de la Cueva, poeta del cancionero Flores de baria poesía”, $C H(7)$, t. 2, p. 802.

12 Stafford Poole, Pedro Moya de Contreras. Catholic reform and royal power in New Spain (1571-1591), University of California, Berkeley-London, 1987, pp. 59-65.

13 Francisco del Paso y Troncoso, Epistolario de Nueva España (1505-1818), Porrúa, México, 1939-1949, t. 11, p. 233. 
tar "don ni promesa, dádiva presente ni otra cosa alguna que no le pertenezca"14.

A tan "alto señor, a quien la ecelsa España/ i el gran Philippo con su cetro embía”, le dirigió Cueva una epístola laudatoria de encumbrados epítetos, confiado también en la justicia, en la equidad y en la represión de los "libres desafueros" por parte del depositario en la ciudad de México del poder real:

Mas pues levanta vuestra fuerte diestra essa vara, levante la justicia a dond'ella levanta a quien l'adiestra, i desnudo esse pecho de codicia cual siempre fue, con la grandeza suya destierre la inclemencia i la injusticia.

La crüeldad se acabe i se destruya, en igual peso puesta la balança sin que del ajustado fiel huya.

Ni el odio á de reynar ni la vengança en el juez, i libre á de estar libre de hazer cosa indina de alabança; que la ley justa al pobre Iro libre o que condene a Crasso, no por esso á de seguir los fueros de Colibre.

Castíguesse el insulto sin ecesso de crüeldad, no más de por castigo, i no por castigar sólo el sucesso ${ }^{15}$.

Las esperanzas del Arzobispo y de nuestro Cueva se vieron frustradas. El buen gobierno del corregidor duró poco, a lo que sabemos. Fue encarcelado y suspendido en el cargo por el virrey Conde de la Coruña, quien nombró por sustituto a Juan de Saavedra el 29 de enero de 1581, por razón de estar Obregón "preso y detenido por horden de los alcaldes del crimen desta Real Audiencia y por delictos de que es acusado"16.

Juan de la Cueva partió de San Juan de Ulúa con destino a España el 22 de abril de 1577, pero su hermano Claudio permaneció en México. Le interesaba hacer carrera en el cabildo de la Catedral lo antes posible. Tuvo compadres en la Audiencia de México y en el Consejo de Indias que cuidaron de sus "pretençiones" y "negoçios" particulares: en Nueva España a los oidores Pedro Farfán y Lope de

14 Libro octavo de actas de cabildo que comenzó en 29 de octubre de 1571 y terminó en fin de diciembre de 1584, Aguilar, México, 1893, p. 134.

15 De las rimas de Ivan de la Cueva, f. 131r-v.

16 Libro octavo de actas de cabildo, p. 477. 
Miranda, acusados de reiterados delitos por Moya de Contreras en la visita de $1583^{17}$; en la corte a poderosos familiares como su tío Carlos de Negrón, fiscal de los consejos de Indias y Hacienda, su primo Andrés Zamudio de Alfaro, médico de cámara de Felipe II, y su sobrino Francisco de Alfaro, regidor de la Villa. Claudio llegó a dar con sus huesos en los calabozos arzobispales de México por su actitud díscola y desobediente, pero, al fin, consiguió su anhelo supremo: ser nombrado agente en Madrid de los intereses de la Catedral Metropolitana, y, en esa consecuencia, velar de cerca por los suyos propios.

Embarcado en abril de 1582 en la flota de tornaviaje, llega a la corte a mediados de octubre y, de inmediato, inicia sus gestiones ante el Consejo de Indias. Pleitea con mayor o menor fortuna en causas diversas. Atraviesa por apuros económicos, acuciado por las deudas que le origina "el trabajo de los negoçios" de la Catedral. "Juro a Vuestra Señoría - escribe desde Sevilla al deán de México el 20 de diciembre de 1583-que el temor de que no he de poder sustentarme en los negoçios y que la neçeçidad me á de hazer desampararlos y venirme a esta çiudad me trae tan mohíno y tan lleno de melancolía, que podré afirmar no haberlo estado jamás en este grado”. Informa ahí que tiene "algunas premisas" que le obligan a no dudar que a don Pedro Moya le ha encomendado el Rey la visita de Nueva España, por lo que recomienda que "procure poner las cosas de esa Yglesia en la orden que conviene" en evitación de complicaciones ulteriores. De intrigas y manejos para sacar tajada en sus propios asuntos, nada de nada. Porque, aclara, "en Madrid ay munchos que tratan de lo que me puede importar con más mano que yo, y, no podiendo ellos, harto menos podré yo"18. Asertos que suenan a hipocresía y a falsedad, ya que sus valedores estaban al acecho aguardando el momento propicio.

Ya en enero de 1570 los capitulares de Guadalajara, en sede vacante por muerte del obispo Ayala, habían encargado un informe al bachiller Gómez de Soria y a Jorge Pérez, tesorero de la Catedral, sobre el estado de Nueva Galicia. Ahí leemos que no existían ni "iglesias votivas ni colegio alguno formado" en la ciudad y que, por el contrario, habían sido ordenados "muchos clérigos idiotas, sin examinar en sus tierras sus linajes y vidas y costumbres"19. De "malos exemplares" y de que no saben gramática y latinidad los curas y frailes del obispado - "y éstos que saven algo desto no saben la lengua de los indios"-

${ }^{17}$ S. Poole, op. cit., pp. 94-100.

18 Archivo de la Catedral de México, Cartas desde 1568 hasta 1634. Reales cédulas, vol. 20, s.f. En adelante, ACM. Respeto los autógrafos de Claudio de la Cueva en su particular ortografía, aunque puntúo, acentúo y hago uso de mayúsculas y minúsculas a la moderna. Deshago algunas abreviaturas.

19 CaRmen Castañeda, La educación en Guadalajara durante la Colonia (1552-1821), El Colegio de México, México, 1984, p. 42. 
se queja al Consejo de Indias el nuevo prelado fray Domingo de Alzola en misiva de 3 de abril de 1584. Refiere ahí que el número de prebendas de la Catedral no estaba todavía cumplido, pero que los capitulares estaban conformes en que no se añadiesen nuevas raciones "por lo que toca a la disminución que de ello les vendría de sus rentas". En todo caso, podría concedérsele algún beneficio -prosigue el prelado- al chantre Juan Antonio de Carmona, que "aunque tiene pocas letras adorna mucho el choro" 20 . Detalle que no debe sorprender por lo exiguo de las rentas y por la falta casi total de clérigos de competencia.

En el entretanto, el Consejo de Indias deliberaba ante la terna de pretendientes que habían hecho relación de méritos para el arcedianato de Guadalajara, vacante por muerte de Bernardo de Quirós. Juan Montaño alegó su condición de hijo de conquistador y encomendero con "cassa poblada y muger y diez y seis hijos", y declaró de sí que era "persona de buena vida y costumbres", conocedor de la lengua náhuatl y que lo apoyaba la Audiencia de México. En caso de no obtenerlo y puestos a pedir, se daba por contento con un curato en las minas de Temascaltépec, en Santa Catalina o en Guadalupe de México o, en último caso, en el real de minas de Pachuca. El segundo era hombre de la casa: el viejo canónigo Jusepe Ramírez, "virtuoso y exemplar" según el informe de 1570. Era el más antiguo prebendado de la Catedral, y dijo en su favor que había obtenido "mucho fruto en la doctrina, por saver bien la lengua de los indios", y que contaba con el respaldo tanto del cabildo eclesiástico como del secular. Por último Claudio de la Cueva, "suficiente y venemérito" según constaba por informes y recados ante el Consejo, racionero de la Iglesia Metropolitana de México, "atento a las caussas por que se le hizo merçed de la dicha raçión"21.

A decir verdad, el Consejo no tenía muy claro si la vacante se había producido por óbito del citado Quirós o por promoción de un tal Juan de Cervantes - supuesto arcediano en Guadalajara desde 1581a la tesorería de la iglesia de Tlaxcala ${ }^{22}$, aunque igual daba una cosa que otra. El 11 de abril de 1584 nuestro "muy virtuoso y letrado" Claudio de la Cueva fue promocionado al arcedianato en litigio ${ }^{23}$. Méritos por encomienda y plácemes locales valieron muy poco frente al poder en la sombra de sus valedores en la corte. En carta de 28 de mayo, con informes diversos sobre sus gestiones, escribió al deán de la catedral de México:

${ }^{20}$ Francisco Orozco y JimÉNez, Colección de documentos históricos inéditos o muy raros, referentes al Arzobispado de Guadalajara, Loreto y Ancira, Guadalajara, 1922-1927, t. 3, pp. 230- 231.

${ }^{21}$ AGI, Indiferente general, 3000, núm. 97, s.f.

22 J. Cebrián, op. cit., p. 23, n. 29.

${ }^{23}$ AGI, Indiferente general, 740, núm. 242. 
En lo que toca a mi particular, escrivo a Vuestra Señoría un bien largo capítulo en la carta que aquí va inserta, que suplico a Vuestra Señoría vea, porque de nuevo me remito a ella; aunque por el nuevo suçeso de averme Su Magestad hecho merçed del arçedianato de Guadalaxara pareçe aver más dificultad que antes avía, respeto de que seré ya computado por estraño; a lo que respondo dos cosas: la primera es jurar a Vuestra Señoría delante de Dios no aver sabido ni imaginado más en esta provisión que en bolverme moro, sino que estos señores proprio motu quizieron hazerme esta merçed, la qual, aunque es tan prinçipal y yo la estimo en muncho, uviera perdonado por particulares respectos míos que se pueden sinificar mal con la pluma. La otra es dar a Vuestra Señoría seguro de mí que ni con ésta ni con otra muy maior ocasión dexaré de servirle en lo que estoy y en otra qualquier cosa en que guste ocuparme (ACM, s. f.).

A poco de enterarse, Juan de la Cueva se congratula del ascenso de su hermano. Compone en remembranza del evento una enaltecida canción petrarquista ${ }^{24}$, abundante en endecasílabos, para "más gravedad i grandeza i manificencia”. El asunto se prestaba a narrarlo en clave de "alabanças" y para "deleites, alegrías i convites", tal como aseveraba Herrera ${ }^{25}$. Por eso, no debe de sorprender que al ponderar "el premio conçedido" por el Consejo de Indias, abunden las hipérboles en las referencias al encomiado, cuyas labores eclesiales entonan las musas Euterpe y Clío y por quien el nombre de Apolo resonará con más fuerza “qu'en tiempo qu'en Delphos fuiste oído”. Que sepamos, Claudio sólo redactó misivas en prosa y algún que otro soneto: uno, a ciencia cierta, en exorno de los preámbulos de Obras de Ivan de la Cveva (ff. 9v-10r). Unos versos elogiosos, de paternidad dudosa, objeto de burlas y censuras en las academias de la época por la sospecha, las más de las veces fundada, de que era el propio autor el que los escribía 26 .

A Cueva, que maneja bien los resortes retóricos del exordio de la épica ${ }^{27}$ - a diferencia de Ercilla, que no refiere en La Araucana (1569) "amorosos afectos y cuidados", sino "el valor, los hechos, las proezas" de la guerra de conquista-28 le mueve "otro furor" por el que espera "lauro eterno". No cantará, como tampoco lo hará Herrera29, "la gloria/ de la guerrera i vitoriosa España,/ ni las naciones que a su yugo

${ }^{24}$ De las rimas de Ivan de la Cueva, ff. 125v-128v. Lo llamaré Cen el aparato crítico del Apéndice.

${ }_{25}$ Obras de Garcilasso de la Vega con anotaciones de Fernando de Herrera, Alonso de la Barrera, Sevilla, 1580, pp. 220 y 250.

${ }^{26}$ José Simón Díaz, "Los apellidos en la poesía de los Siglos de Oro", RLit, 1 (1952), 47-55.

27 Antonio Prieto, Estudios de literatura europea, Narcea, Madrid, 1975, pp. 15-71.

28 Alonso de Ercilla, La Araucana, eds. M. A. Morínigo e I. Lerner, Castalia, Madrid, 1979, t. 1, p. 127.

${ }^{29}$ Algunas obras de Fernando de Herrera, Andrea Pescioni, Sevilla, 1582, f. 53r-v. 
á puesto/ su immortal valentía i su memoria"30. "Otro" habrá de ser pues quien armonice en epicidad la derrota de los turcos a las puertas de Viena (1529) o la de Francisco I en Pavía (1525) y su posterior encarcelamiento en España, "a la cadena azido/ del gran monarcha que su ardor refrena". Relatará, por el contrario, en "canto desigual" al "valor" y al "ingenio divino" del enaltecido, el "premio" concedido por Felipe II a su "lealtad i fe i justicia" y "demás virtudes ecelentes", entre las que se encuentran, como no podía ser menos, sus dotes evangelizadoras:

\author{
que si la vencedora \\ mano del gran Philippo con largueza \\ remuneró vuestra virtud, fue cierto \\ del tesoro qu'en vos tenía cubierto; \\ i assí siguiendo su real grandeza, \\ al mundo á descubierto \\ con esse premio el premio que se deve \\ a quien lealtad i fe i justicia mueve. \\ Éstas haziendo en vos su firme assiento, \\ con las demás virtudes ecelentes \\ que espiran esse pecho generoso, \\ dando vuestro valor conocimiento, \\ que no entendido en partes differentes \\ lo encubría el olvido riguroso, \\ i el cielo glorïoso \\ por la salud del bárbaro ignorante \\ i que su alma a la región divina \\ encamine, le da por medicina \\ que la fecunda boz vuestra le cante \\ la celestial dotrina, \\ con que será instruida su rudeza \\ i en el camino de la heterna alteza
} (ibid., ff. 126v-127r).

Pese a tan exaltados halagos, Claudio de la Cueva no viajó a Guadalajara y, en esa consecuencia, no llegó a ocupar el arcedianato de la Catedral. Nunca más regresó a Nueva España. Decidió no aceptar la prebenda por lo exiguo de la renta. ¿Acaso podría medrar un clérigo ambicioso, como él era, en diócesis tan indigente? De hecho, el obispo Alzola, en carta al Consejo de 1586, se queja de que los canónigos de la catedral neogallega "pasaban con harta pobreza". Y aún más al haberse provisto los honores de arcediano y tesorero, pues "viene a 
disminuírseles a todos su renta tan notablemente que, sin duda, pasarán con mucha pobreza y trabajo quando todas dignidades y canongías estuvieren presentes" 31 . Por fortuna para sus estómagos, no llegaron a ocuparse todas las vacantes. Francisco de Morales ( $† 1593)$ desempeñó la tesorería desde el 12 de febrero de $1585^{32}$. En cambio, no hubo nuevo arcediano hasta que en 1591 cubrió la plaza el licenciado Luis de Robles ${ }^{33}$.

En junta de 2 de octubre el cabildo de la catedral de México supo que "el dicho doctor es prebendado de otra iglesia" y acordó que siguiese gozando de salario hasta el término de los tres años de su nombramiento como agente en la corte ${ }^{34}$. Por poco tiempo, ya que días más tarde le fue notificado al mayordomo Andrés de la Rosa que no le acudiese con más dineros. Protestó su amigo el canónigo Alonso López de Cárdenas, aunque en balde. Desde ese momento dejó de pertenecer a la iglesia que había servido por espacio de diez años (ibid., f. 206v).

Así pues, ni Claudio ni Juan de la Cueva estuvieron nunca en Guadalajara. El primero era por septiembre de 1585 abogado de presos de la Inquisición de Sevilla. El poeta andaba por entonces redactando el Viaje de Sannio y acumulando en su alter ego los resabios de sus "hambres i passiones" y su "estrecho menester i desventura". Ambos moraban en el "dulce i patrio nido" por el que habían suspirado desde el ya lejano y distante México ${ }^{35}$.

José Cebrián

${ }^{31}$ F. OROZCO y JimÉNeZ, op. cit., t. 3, pp. 245-246.

32 Archivo de la Catedral de Guadalajara, Libro 3 de cabildos (1583-1598), f. 14r. Morales siguió ejerciendo el cargo varios años más, y así consta en las Actas. Se equivoca EucArio López ("El Cabildo de Guadalajara. 1 de mayo 1552-1 de febrero 1568. Elenco", Anuario de la Comisión Diocesana de Historia del Arzobispado de Guadalajara, Jus, México, 1968, p. 186) al decir que Cueva era tesorero de la Catedral en octubre de 1587. En la relación capitular de ese año, donde sí aparece como tesorero Francisco de Morales, no hay el más mínimo rastro de Cueva. Tampoco en las Actas de la Catedral, por supuesto. Véase al respecto Félix Zubillaga, Monumenta Mexicana, Monumenta Historica Societatis Iesu, Romæ, 1956-1971, t. 3, p. 224.

${ }^{33}$ ACG, Libro 3 de cabildos, f. 88r.

34 ACM, Libro 3 de cabildos. Año de 1576 hasta el de 1588, ff. 204v-205r.

${ }^{35}$ De las rimas de Ivan de la Cueva, f. $74 \mathrm{r}-\mathrm{v}$. 


\section{APÉNDICE* \\ CANCIÓN VII ${ }^{\mathrm{a}}$ \\ Al dotor Claudio de la Cueva, inquisidor apostólico \&cc., aviéndole dado el arcedianato de Guadalajara en las Indias de la Nueva España}

Acuerda con tu lira el canto mío, onor de Cynthio, Phebo glorioso, celebremos el premio concedido al joben que çelebra Euterpe i Clío i por quien oy tu nombre es más famoso qu'en el tiempo qu'en Delphos fuiste oído.

No cubra el letheo olvido con sombra oscura la memoria eterna del qu'en la gloriosa virtud santa con levantado buelo se levanta, pues ella dél i él della se govierna, cual ella mesma canta con boz divina con que al tiempo ecede i le atribuye cuanto a sí concede.

No quiero en esto celebrar la gloria de la guerrera i vitoriosa España, ni las naciones que a su yugo á puesto su immortal valentía i su memoria, que Apolo que m'aspira i m'acompaña guía mi estilo a diferente puesto. Ocúpese otro en esto, cante del fiero bárbaro en Viena desbaratado i del francés rendido, su fuerte rey a la cadena azido del gran monarcha que su ardor refrena, que aora soy movido de otro furor, por quien me guío i govierno, que promete a mi musa lauro eterno.

El canto desigual al valor vuestro i al ingenio divino que os dio el cielo, Claudio ecelente, no os disuene aora porque con osadía tal demuestro parte de vuestra gloria al baxo suelo,

* Aplico al texto del apéndice los criterios ecdóticos usuales en mis ediciones (véase, por ejemplo, Juan de la Cueva, Viaje de Sannio, Miraguano, Madrid, 1990, pp. xxviii-xxi). El aparato crítico -ligero, pues es copia autógrafa de testimonio único- incluye errores y enmiendas. Entre corchetes, la remodelación o enmienda escrita sobre banderillas; entre llaves, las lecciones autógrafas ocultas bajo las mismas.

a Testimonio único: $C$, ff. 125v-128v, canción 7 . 
a quien la Fama i la Virtud adorab, que si la vencedora

mano del gran Philippo con largueza

remuneró vuestra virtud, fue cierto

del tesoro qu'en vos tenía cubierto;

i assí siguiendo su real grandeza,

al mundo á descubierto

con esse premio el premio que se deve

a quien lealtad i fe i justicia mueve.

Éstas haziendo en vos su firme assiento, con las demás virtudes ecelentes que espiran esse pecho generoso,

dando vuestro valor conocimiento, que no entendido en partes differentes

lo encubría el olvido riguroso,

i el cielo glorioso

por la salud del bárbaro ignorante

i que su alma a la región divina

encamine, le da por medicina

que la fecunda boz vuestra le cante

la celestial dotrina,

con que será instruida su rudeza

i en el camino de la heterna alteza.

Pues ¡ea ya! luz clara, norte i guía

de la virtud, la lengua dezatando

su ceguedad le manifieste al mundo

entienda la baxeza en que confía,

la vanidad que sigue, despreciando

lo qu'el bien le promete sin segundo;

de un sueño tan profundo

la recuerde, no reyne el avaricia,

destiérresse la ira i aspereza,

huyga d'entre los ombres la crüeza,

tenga su firme cetro la justicia;

viva con la pureza

que vivir deve, sin que pueda fuerça

hazer que la balança justa tuerça.

Conosca el temeroso siglo nuestro que por vos se mejora i perfeciona,

i levante de bronze una figura

en alabança vuestra i nombre vuestro,

pues el sagrado coro d'Elicona

la boz esparze de immortal dulçura.

b [a quien la Fama i la Virtud adora] \{Rayado e ilegible, luego sobrescrito a quien la Fama i la Virtud adora\} 
Esculpa en piedra dura

que viva lo qu'el cielo en su carrera,

no el blasón vuestro antiguo i celebrado,

de aquel varón ilustre derivado

qu'en la Cueva al dragón dio muerte fiera, mas las letras i estado,

religión i virtud resplandeciente,

digna de vuestro ánimo ecelente.

Tended la generosa i larga mano

que sustenta la palma vitoriosa

que de la invidia os á otorgado el cielo,

i los ojos bolved a ver hufano

por nueva tan alegre i venturosa

a vuestro hesperio, dulce i patrio suelo;

i si el ligero buelo

de la vida la muerte no me corta,

yo libraré de olvido vuestro nombre

sin que la invidia que la gloria acorta

lo impida, ni aya ombre

que lo ignore, pues esto es otorgadoch a aquél qu'es a las Musas dedicado.

La vida instable a quien el curso breve

de la severa Parca está sugeta,

con ningún medio humano se repara,

que por orden factal es ley que prueve

el trago horrible i llegue a aquella meta

donde lo que principio tuvo para.

La edad presta id avara,

que siempre en su carrera va delante,

deshaze de los montes l'aspereza,

umilla de las cumbres el alteza,

ablanda la dureza del diamante;

imperios, fortaleza

en polvo ${ }^{\mathrm{e}}$ i sombra vana se convierte,

i los versos lo libran de la muerte.

\footnotetext{
c Falta el endecasílabo que rima con éste, pero no por error de copia sino de cómputo.

ch [pues esto es otorgado] \{que aquesto es otorgado\}

d y Error ortográfico de copia.

e em polvo Error de copia por sustitución.
} 